\title{
Double flashes from single pulses of light
}

\author{
ROBERT M. SPRINGER \\ Xerox Corporation, Rochester, New York 14603 \\ J. ANTHONY DEUTSCH \\ University of California, San Diego, La Jolla, California 92037 \\ and \\ GORDON STANLEY \\ University of Melbourne, Melbourne, Australia
}

\begin{abstract}
Under some conditions, a single pulse of light appears as two. The following parameters of the double-flash phenomenon were studied in two experiments: room illumination, stimulus size, peripheral angle of viewing, latency between the two flashes, and flash wavelength. It was found that the phenomenon only appeared consistently under mesopic levels of white or green illumination and from 13 to $55 \mathrm{deg}$ peripherally. The mean latency between the flashes was estimated at $104 \mathrm{msec}$. The data are considered to support an explanation in terms of differential latency between the rod and cone systems.
\end{abstract}

It has been known for a long time (Dunlap, 1915) that a single photic pulse can sometimes appear as two flashes. The precise conditions under which doubling occurs are in doubt (Boynton, 1972), and, as a consequence, the explanation of the phenomenon is somewhat unclear.

Preliminary observations by the present authors showed that the overall level of adaptation of the observer is critical in obtaining two flashes, and that the phenomenon does not occur when the flash is fixated directly. On the basis of this finding, it was considered likely that the double flash was due to differential latency between the rod and cone systems, as first suggested by Bartley and Wilkinson (1953). Given this explanation, several parameters would be expected to affect the phenomenon. In Experiment I, stimulus size, retinal location, and adaptation level were varied. Experiment II provided an estimate of the latency between the two flashes to enable comparison with physiological data on the differential between rod and cone latency.

Finally, a pilot study was performed in which the double-flash phenomenon was evaluated with short, medium, and long wavelength light equated in photopic luminance.

\section{EXPERIMENT I}

\section{Method}

Subjects. Five male and five female volunteers serves as subjects. They had normal or corrected-to-normal vision and were naive with respect to the phenomenon being studied.

This study was carried out while the third author was a visitor at the Center for Human Information Processing at the University of California, San Diego. The experiments were supported in part by NIMH Grant MH-15828 to the Center.
Apparatus. The subjects sat within an acoustically treated chamber and binocularly viewed stimuli, presented at eye level. within a Scientific Prototype two-field tachistoscope situated 21 in in front of the subject. Except for the exist opening, the tachistoscope was hidden by a large vertical black screen attached to the outside front of the tachistoscope. The screen was extended on the subject's right side along a 21 -in. horizontal radius about the subject's nasal bridge. White vertical fixation marks were placed on the screen at 5-seg steps along the horizontal visual plane to the right of optical center.

The stimuli comprised three rectangles of light subtending areas of $3.5,16.4$, and $27.2 \mathrm{deg}^{2}$. The rectangles, having a length-to-wid th ratio of approximately $2: 1$, were presented with the length along the horizontal. The rectangles were formed by uniformly illuminating frames situated within the tachistoscope. The stimuli were presented at a luminance of $1.0 \mathrm{~cd} / \mathrm{m}^{2}$ for a duration of $10 \mathrm{msec}$; flashes were repeated at an interval of $750 \mathrm{msec}$. To check the possibility that double flashes were caused through transients in the electronic circuitry of the tachistoscope, the pulse characteristics were tested using a Tektronix 564 cathode-ray oscilloscope and a photocell.

Procedure. The subject was seated in front of the tachistoscope and instructed to fixate straight ahead, at the center of where the rectangle of light was being pulsed. After a few seconds, the subject was then instructed to look peripherally at the fixation point, which was $15 \mathrm{deg}$ to the right of center, to observe the pulses, and to indicate if there were any differences in appearance between the pulses for the two conditions of viewing. All subjects reported a difference. Their descriptions varied from saying that the peripheral view produced "two flashes" to saying that there was additional "flicker." They were instructed to keep the criterion of difference between the straight-ahead and the peripheral conditions as the basis for the judgment of "flicker" or "no flicker."

A method of adjustment was used to determine where in the visual field the flicker commenced and where it ceased. The subject was required to make estimates as he moved his head from the straight-ahead position to varying positions in the right field. Then the procedure was reversed. The point beyond which no flicker occurred in the peripheral field was determined in a similar manner.

Experimental dexign. The level of illumination in the subject's booth was set at $0.49 \mathrm{~cd} / \mathrm{m}^{2}$, and, on entering, the subject made estimates of where in the visual field onset and offset of the flicker for each size of stimulus occurred. After $12 \mathrm{~min}$, these judgments 
were repeated. Then the overall room illumination was set at $15.9 \mathrm{~cd} / \mathrm{m}^{2}$, and the subject made estimates of the boundaries of flicker only for the large rectangle. After $12 \mathrm{~min}$, the room lights were turned off and the subject dark-adapted for $15 \mathrm{~min}$. At approximately 3-min intervals during both of these adaptation periods, the experimenter requested judgments from the subject; again, only the large rectangle was employed. Final judgments were made after 15 min of dark adaptation.

\section{Results}

As mentioned in the procedure section, all 10 subjects experienced the double-flash phenomenon under the mesopic $\left(0.5 \mathrm{~cd} / \mathrm{m}^{2}\right)$ condition, in line with our preliminary observations. The two estimates for each location were averaged, and these estimates were analyzed in a two-factor, Rectangle Size (small, medium, and large) by Time of Observation (during first $12 \mathrm{~min}$, after $12 \mathrm{~min}$ ), analysis of variance. Two analyses of variance were computed, one for the onset angle and one for the offset angle. For both onset and offset angle, neither rectangular size $[\mathrm{F}(2,18)=3.34$ and $F(2,18)=3.46$, respectively, $p>.05$ ] nor time ( $F<1$ in both cases) were significant. The onset angle averaged over all conditions was $13.86 \mathrm{deg}$, and the offset angle was $55.29 \mathrm{deg}$.

For the photopic $\left(1.59 \mathrm{~cd} / \mathrm{m}^{2}\right)$ condition, a few subjects reported seeing the double flash during the first $3 \mathrm{~min}$. However, no subject reported the double flash after 6 min light adaptation. Similarly, for the scotopic condition, a few subjects observed the double flash during the first $5 \mathrm{~min}$, but no subject reported double tlashes after $5 \mathrm{~min}$. Thus, the phenomenon is reported consistently only under mesopic conditions.

\section{EXPERIMENT II}

\section{Method}

Subjects. Five male and five female volunteers served as subjects. Some were sophisticated with regard to the two-flash phenomenon.

Apparatus. The apparatus was as in Experiment I, except that a second stimulus was presented above the first by means of another tachistoscope. The fields were separated by an angle of $14.5 \mathrm{deg}$. and the area of the rectangles in both fields was $27.2 \mathrm{deg}^{2}$. Overall room illumination was constant at $0.49 \mathrm{~cd} / \mathrm{m}^{2}$.

Procedure. The subjects were instructed to fixate the upper rectangle and to view the lower one peripherally. The upper rectangle was double pulsed and the interpulse interval was varied by the experimenter in both an up and a down limits procedure. The subject was instructed to indicate when the flash rate of the upper stimulus appeared equal to that of the lower stimulus, which was singly pulsed. Pulse duration was fixed at $10 \mathrm{msec}$.

\section{Results}

When questioned at the conclusion of the judgments, all the naive subjects believed that the lower stimulus was physically double-pulsed. When allowed to fixate the lower rectangle after the experiment, they expressed surprise at seeing only one flash. The mean interpulse interval matching the two-tlash from the single-pulse stimulus was 104.25 $( \pm 3.1)$ msec.

\section{DISCUSSION}

If the double-flash phenomenon is a consequence of a differential in rod and cone latency, the phenomenon should never appear when only rods or cones are active. It is generally believed that at photopic levels the cones inhibit the rods, while at mesopic levels and scotopic levels of adaptation both populations can be activated; double flashes should not occur at a photopic level. Single flashes should be seen in the fovea and far periphery; double flashes should arise only in some intermediate mixed receptor region. The double-flash phenomenon should be dependent upon the wavelength of the stimulus. Finally, the latency between flashes should approximately match well-known indices of the rod-cone latency differential.

The double-flash effect was, in fact, found to be absent at a photopic adaptation level; moreover, only single flashes were observed when the stimulus was nearer than $13 \mathrm{deg}$ or father than $55 \mathrm{deg}$ from the fovea. In addition, the 104-msec latency is not grossly different from the 80-90-msec differential between the peaks of the ERG wave rod and cone components (Armington, Johnson, \& Riggs, 1952). But what of the disappearance of the phenomenon at scotopic adaptation levels? At this level of adaptation, both receptor populations should be stimulable.

We may note that the region 13 to $55 \mathrm{deg}$ from the fovea where the phenomena occurred is a predominantly rod region; it appears that a larger rod than cone signal is necessary for transmission when the cones are also activated. It is probably not too implausible to speculate that if cone inhibition of rods exists to a moderate degree at mesopic levels, and strongly at photopic levels, a strong rod signal at scotopic levels may inhibit the cones to some degree again leading to a single-flash report.

This contention is strengthened by the results of a pilot study in which three subjects, mesopically adapted, observed the 27.2-deg rectangle illuminated by short-, middle-, and long-wavelength light about $25 \mathrm{deg}$ lateral to the fovea. Luminance was adjusted (using neutral density filters and the bulb voltage control) to keep the light level for each condition at $1.0 \mathrm{~cd} / \mathrm{m}^{2}$ (photopic luminosity). Luminosity was verified with a United Detector $80 \mathrm{X}$ photometer containing a calibrated photopic luminosity filter. Flash duration was again $10 \mathrm{msec}$. Each subject first reaffirmed that the double-flash effect readily occurred with unfiltered illumination (standard unfiltered Scientific Prototype fluorescents). Next, one of three filters (Wratten 25, 47, or 58) was inserted in front of the stimulus and the luminosity adjusted to $1 \mathrm{~cd} / \mathrm{m}^{2}$. The results support the hypothesis of a rod-cone interaction. At middle 
(Wratten 58 "green") wavelengths, the double-tlash phenomenon was readily apparent, although it was difficult to judge whether both flashes appeared to be chromatic: the rod signal was apparently unchanged from its strong level under unfiltered illumination. At short wavelengths (Wratten $47^{\text {" }}$ blue "). only a single. quite achromatic. flash was visible (although occasionally a simultaneous blue sensation was reported to occur in the forea); since light in this region stimulates the rods much more strongly than the cones. our contention of rod inhibition of cones appears confirmed. Finally. at long wavelengths (Wratten 25 "red"). only a single, vividly red, flash was visible. Since rod and cone stimulation to long wavelengths is nearly equal at these wavelengths, our earlier speculation that a stronger rod than cone signal is necessary (at mesopic levels) to overcome cone inhibition seems to be supported. ${ }^{1}$

It should be possible to restore the double-flash phenomena in these single-flash conditions by altering the flash strength in conjunction with the adaptation level. Moreover. it would be of interest to study the double-flash phenomena where the flash stimulus consisted of wavelengths from two different spectral regions each at different luminances. Here it would be expected that rod and cone populations could be individually manipulated to further test the inhibition hypothesis put forth in this paper.

\section{REFERENCES}

Armington. J. C.. Johnson. E. P.. \& Riggs, L. A. The scotopic A-wave in the electrical response of the human retina. Journal of Physiologi, 1952. 118. 289.298.

Bartley. S. H., \& Wilkinson. F. R. Certain factors in producing complexity of response to a single pulse of light. Journal of Psychology. 1953. 35. 299-306.

BoyntoN. R. M. Discrimination of homogeneous double pulses of light. In D. Jameson and L. M. Hurich (Eds.). Visual psychophysics. Handbook of senson physiology (Vol. VII 4). New York: Springer-Verlag. 19-2.

Dinlap. K. The shortest perceptible time interval between twu flashes of light. Psychological Review. 1915. 22. 226-250.

\section{NOTE}

1. The authors would like to thank B. Tansley for pointing this out.

(Received for publication January 15, 1973; revision received August 11. 1975.) 